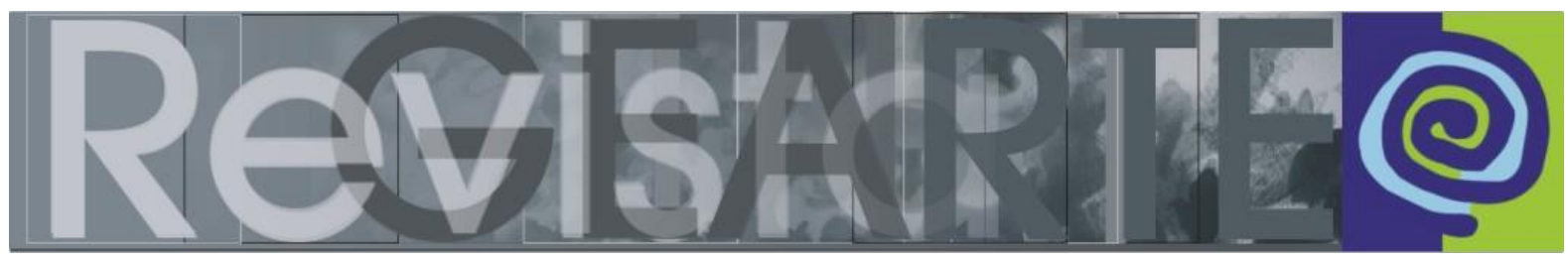

e-ISSN 2357-9854

\title{
A luz da fotografia: experiência de registro da percepção sobre o patrimônio arquitetônico na cidade de Brotas
}

\author{
Jessica Aline Tardivo (Universidade de São Paulo - USP, São Paulo/SP, Brasil) \\ Anja Pratschke (Universidade de São Paulo - USP, São Paulo/SP, Brasil) \\ Maria Clara Cardoso (Universidade de São Paulo - USP, São Paulo/SP, Brasil)
}

RESUMO - A luz da fotografia: experiência de registro da percepção sobre o patrimônio arquitetônico na cidade de Brotas - $\mathrm{O}$ artigo relata e analisa a experiência educativa ${ }^{1}$ realizada na cidade de Brotas, interior do Estado de São Paulo, destinada a adolescentes de 13 a 16 anos, cujo método fundamentado no conceito de Educação Patrimonial, sistematizado no ano de 1999 pela museóloga brasileira Maria de Lourdes Parreiras Horta (HORTA, 1999), teve por objetivo aproximar os indivíduos do patrimônio arquitetônico retratando a percepção de cada um por meio do registro e manipulação fotográfica. Para melhor compreensão do processo dividiu-se este ensaio em três partes: a primeira (1) apresenta registros cognitivos na cidade contemporânea; a segunda (2) relata a ação educativa; o terceiro (3) analisa os resultados da ação.

PALAVRAS-CHAVE

Educação Patrimonial. Patrimônio Arquitetônico. Registro.

ABSTRACT - The light of photography: experience of recording the perception of the architectural heritage in the city of Brotas (SP) - This article reports and analyzes the educational experience in the city of Brotas, in the interior of the State of São Paulo, aimed at adolescents from 13 to 16 years old, whose method is based on the concept of Heritage Education, systematized in the year 1999 by the Brazilian museologist Maria de Lourdes Parreiras Horta (Horta, 1999), aimed to approximate the individuals of the architectural patrimony portraying the perception of each one through the photographic register and manipulation. For a better understanding of the process, this essay was divided into three parts: the first one (1) presents cognitive registers in the contemporary city; the second (2) reports the educational action; the third (3) analyzes the results of the activity.

\section{KEYWORDS}

Heritage Education. Architectural Heritage. Register.

\section{Mapeamento visual da arquitetura nas cidades contemporâneas}

Ao mapear a arquitetura das cidades contemporâneas, que vivenciam novas formas de comunicação mediadas pelos usos de meios e recursos digitais, é requerido

a observação dos resquícios do passado, anexados às construções presentes e

1 A experiência educativa faz parte da pesquisa de doutorado da primeira autora, financiada pela Capes, e do estudo de caso da Iniciação cientifica da terceira autora, financiado pela Fapesp, ambas orientadas pela profa. Dra. Anja Pratschke. 
projeções futuras. De acordo com os estudos dos filósofos franceses Gilles Deleuze e Félix Guattari (1980, p. 21), o mapeamento da cidade é um processo cognitivo de experimentação do indivíduo sobre o espaço real, "não há um sentido único no processo, podendo-se encontrar múltiplas realidades e significações sobre o lugar. No entanto para a arquiteta e pesquisadora israelense Tali Hatuka (2017, p. 51), o registro da cidade hoje seria uma "colagem de mapas mnemônicos", que refletem as transformações do tempo e os diferentes modos de vida.

Sobre essa observação, os trabalhos visuais da artista e publicitária americana Hilary Williams, que emprega colagem com serigrafias e pinturas na construção de novas paisagens urbanas, e da arquiteta e artista brasileira Virgínia Dolabela, que faz uso de fotomontagens digitais para leitura cultural e social da cidade, revelam de forma gráfica, essa colagem de diferentes perspectivas da cidade, citada por Hatuka, construindo plasticamente uma cartografia cognitiva da cidade hoje. Ambas artistas, inspiradas nos movimentos artísticos do Dadaísmo, Surrealismo e Pop Arte, buscam com auxílio da fotografia e dos recursos digitais representar suas interpretações dos espaços e lugares da cidade.

Willians, utiliza de técnicas mistas de colagem, que facilitam a sobreposição das imagens reais e imaginárias percebidas no lugar, compondo uma paisagem mnemônica que representa a sua percepção dada pela imagem mental. Como exemplo o trabalho "Dez noites fora do Porto" (Ten Evenings Off the Port)2. No trabalho a artista expõe uma realidade alterada da cidade, composta pela sobreposição de imagens de edificações, objetos estruturais, mobiliários urbanos diversos, letreiros com propagandas e partes do paisagismo natural, revelando através de sua percepção a identidade do lugar. Sobre esse apontamento Wilians responde:

[...]. Eu me esforço para fazer peças densas que lidam com o absurdo e a perversidade do nosso mundo, rindo, chorando ou ficando de pé com admiração. Uso colagens de fotografia, desenho, pintura e modelagem para criar camadas de imagens e significado. Meus trabalhos lidam com uma variedade de emoções sobre a coexistência de nossa paisagem urbana, natureza e humanidade. Estou

2 Ver em <http://www.hilaryatthecircus.com/digital/> Acesso em 01 fev. 2018. 
continuamente inspirado pelo meio ambiente, pelos ambientes urbanos e naturais de hoje[... $]^{3}$ (JORNAL PRIMEIRA EMENDA, 2010, p. 1)

Assim como Willians, Dolabela cria paisagens singulares da cidade, utilizando como suporte fotografias autorais, editadas e sobrepostas, com o propósito de apresentar detalhes que nem sempre são percebidos nos espaços urbanos, mas que são de suma importância para a construção social e para o entendimento da memória na cidade hoje. Como exemplo as obras de Fotocolagem realizadas para a série digital Sagrado e Profano 4 . Por meio da Fotocolagem de Dolabela, pode-se notar pequenos recortes da rotina na cidade que tramam o movimento dos indivíduos, a arquitetura, a arte e o mobiliário urbano. $O$ cenário final materializa a percepção crítica da artista possibilitando ao observador construir múltiplas narrativas e reflexões sobre a cidade contemporânea. Entende-se nesse breve estudo que partindo dos mesmos referenciais artísticos, porém com abordagens distintas, as artistas viabilizam que observadores e expectadores do trabalho visualizem os conflitos urbanos e construam interpretações pessoais sobre a cidade e sobre as percepções expostas nas obras.

\section{Experiência de registro mnemônico na cidade de Brotas}

Pautando-se no apresentado, fez-se uso da metodologia de pesquisa intervenção, com caráter qualitativo de investigação de experiências, para a construção de um sistema mnemônico que permitisse conhecer a arquitetura da cidade de Brotas por meio de um percurso fotográfico, adaptando-se as quatro etapas de Educação Patrimonial, a saber: (1) Observação, (2) Registro, (3) Exploração e (4) Apropriação, conforme ilustra a Tabela 1. A ação teve a duração de três dias e contou com a participação de vinte pessoas, entre elas sete meninos e treze meninas, alunos do ensino fundamental II da Escola Municipal Álvaro Callado, que estiveram em

3 Do original: [...] I strive to make dense pieces that deal with the absurdity and poignancy of our world by laughing, crying, or standing back in awe. I use collages of photography, drawing, painting, patterning to create layers of images and meaning. My works deal with a variety of emotions about the coexistence of our urban landscape, nature, and humanity. I am continually inspired by my surroundings, today's urban and natural environments [...].

4 Ver em :<https://virginiadolabela.blogspot.com.br>. Acesso em 01.fev.2018.

TARDIVO, Jessica Aline; PRATSCHKE, Anja; CARDOSO, Maria Clara. A luz da fotografia: experiência de registro da percepção sobre o patrimônio arquitetônico na cidade de Brotas (SP) Revista GEARTE, Porto Alegre, v. 5, n. 2, p. 326-336, maio/ago. 2018.

Disponível em: http://seer.ufrgs.br/gearte 
contato com quatro alunos do curso de graduação de arquitetura e urbanismo e mediados pelas pesquisadoras deste trabalho.

Tabela 1. Etapas de Educação Patrimonial.

\begin{tabular}{|c|c|c|}
\hline ETAPAS & RECURSOS/ATIVIDADES & OBJETIVOS \\
\hline 1. Observação & $\begin{array}{l}\text { Percurso fotográfico com auxílio de } \\
\text { dispositivos móveis }\end{array}$ & $\begin{array}{c}\text { Identificação do objeto e percepção } \\
\text { visual }\end{array}$ \\
\hline 2. Registro & $\begin{array}{c}\text { Construção de um mapa mental com } \\
\text { auxílio da planta da cidade e } \\
\text { marcadores de papel }\end{array}$ & $\begin{array}{c}\text { Aprofundamento da observação e } \\
\text { análise crítica }\end{array}$ \\
\hline 3. Exploração & $\begin{array}{l}\text { Análise dos objetivos, construção de } \\
\text { texto sobre a observação }\end{array}$ & $\begin{array}{c}\text { Desenvolvimento das capacidades } \\
\text { de análise crítica e interpretação das } \\
\text { evidências e significados }\end{array}$ \\
\hline 4. Apropriação & $\begin{array}{l}\text { Releitura da cidade por meio de uma } \\
\text { Fotocolagem digital, com auxílio de } \\
\text { softwares de edição de imagem }\end{array}$ & $\begin{array}{c}\text { Participação criativa para o } \\
\text { envolvimento afetivo e valorização do } \\
\text { bem cultural }\end{array}$ \\
\hline
\end{tabular}

Fonte: Adaptação das Etapas de Educação Patrimonial, Arquivo da pesquisa.

Etapa 1 (Observação): A cidade de Brotas, fundada no ano de 1859, não faz parte das cidades tombadas no país, conquanto apresenta um conjunto de edificações com estilo eclético do início do século XX. Tais são dispostas entre construções e mobiliários urbanos atuais, que são cercados pela paisagem natural significantemente marcada pelo trajeto do Rio Jacaré Pepira, o qual serpenteia o centro da cidade, formando por meio da topografia de pequenas quedas d'agua que resultam em uma paisagem urbana diferenciada. Para abranger e conhecer os detalhes desse conjunto, dividiu-se o objeto de estudo em quatro eixos de observação: (1) Grades e Ferragens; (2) Aberturas e Mobiliário Urbano; (3) Ornamentações e (4) Paisagismo e Elementos Visuais. Conforme ilustra a Figura 1. 
Figura 1. Eixos de observação.

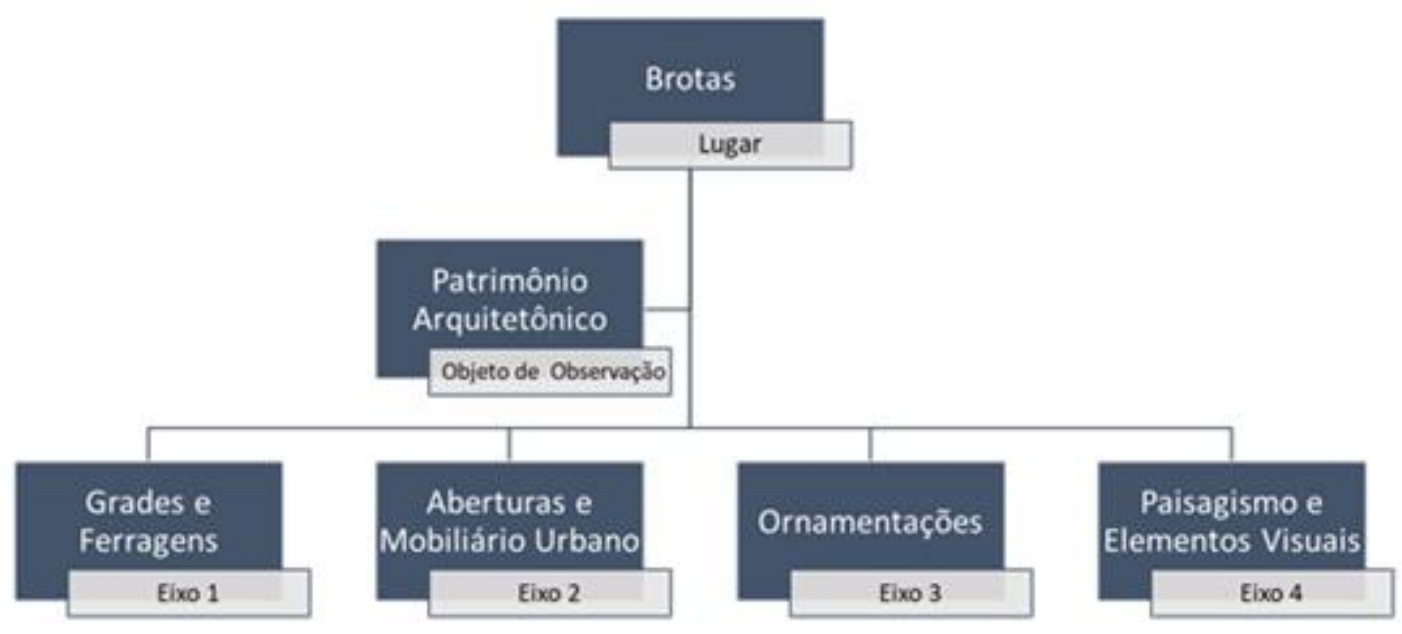

Fonte: Arquivo da pesquisa.

Os participantes foram divididos em quatro equipes, cada uma responsável por um eixo de observação. O percurso fotográfico percorreu a Avenida Dr. Mário Pinotti, rua central da cidade que percorre a malha urbana de uma ponta a outra, em um período total de quatro horas. Os alunos observaram a arquitetura por meio das lentes de seus dispositivos móveis, conforme ilustra a Figura 2.

Figura 2. Alunos registrando a cidade durante o Percurso Fotográfico

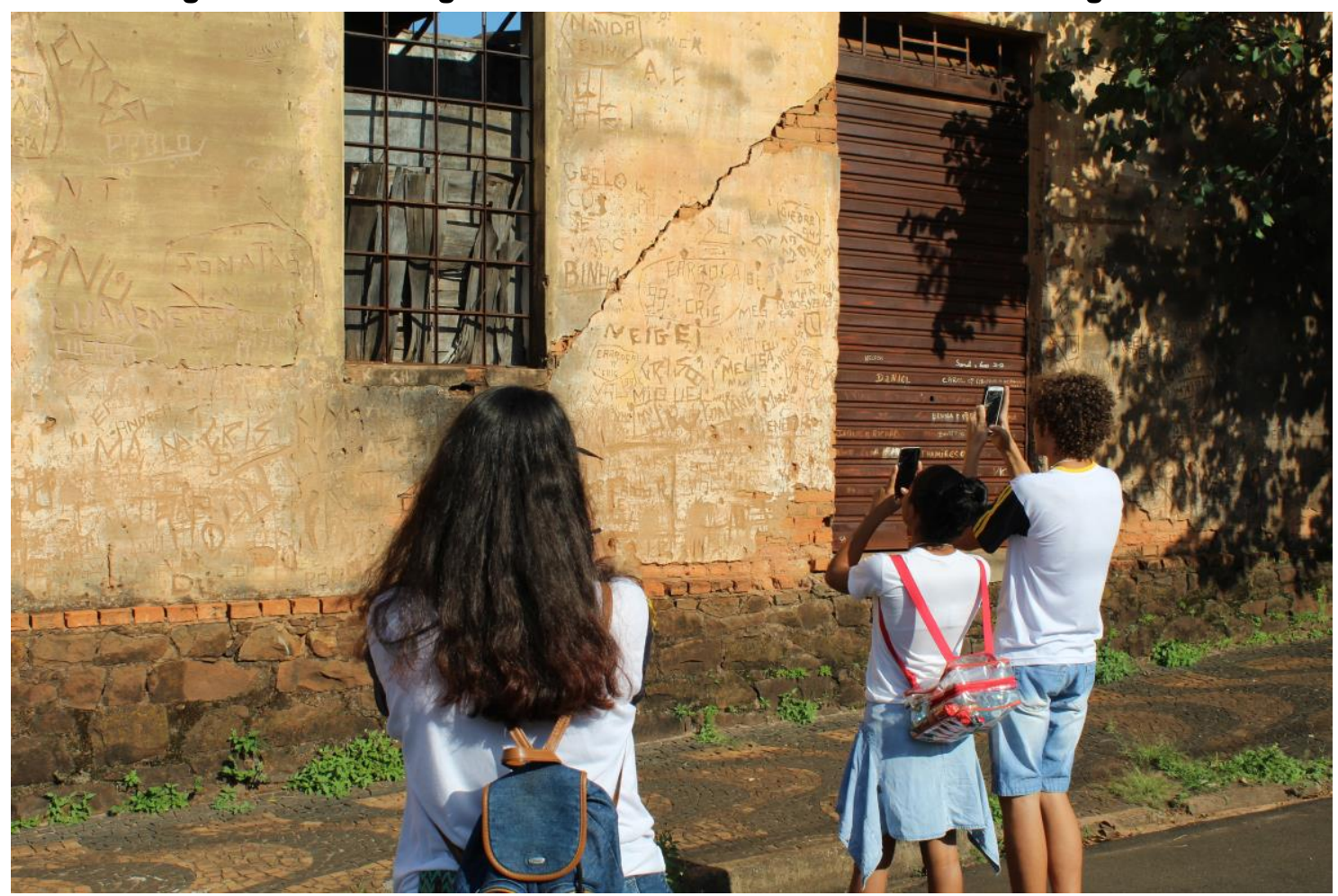

Fonte: Arquivo da pesquisa, Brotas, 2018.

TARDIVO, Jessica Aline; PRATSCHKE, Anja; CARDOSO, Maria Clara. A luz da fotografia: experiência de registro da percepção sobre o patrimônio arquitetônico na cidade de Brotas (SP) Revista GEARTE, Porto Alegre, v. 5, n. 2, p. 326-336, maio/ago. 2018.

Disponível em: http://seer.ufrgs.br/gearte 
Etapa 2 (Exploração): A fim de possibilitar uma análise crítica do processo de observação, os participantes construíram um mapa mental, ou seja, pontuaram os detalhes arquitetônicos encontrados sob um mapa impresso do lugar, conforme ilustra a Figura 3. Nesta os envolvidos puderam conversar sobre suas impressões, ressalvando os bens culturais que já conheciam e outros que não haviam percebido. A percepção de cada um dos alunos colaborou para a constituição de uma rede de referências que acaba por estimular as lembranças dos demais, dessa forma se ressalta a característica coletiva de construção da memória.

Figura 3. Construção do Mapa Mental.

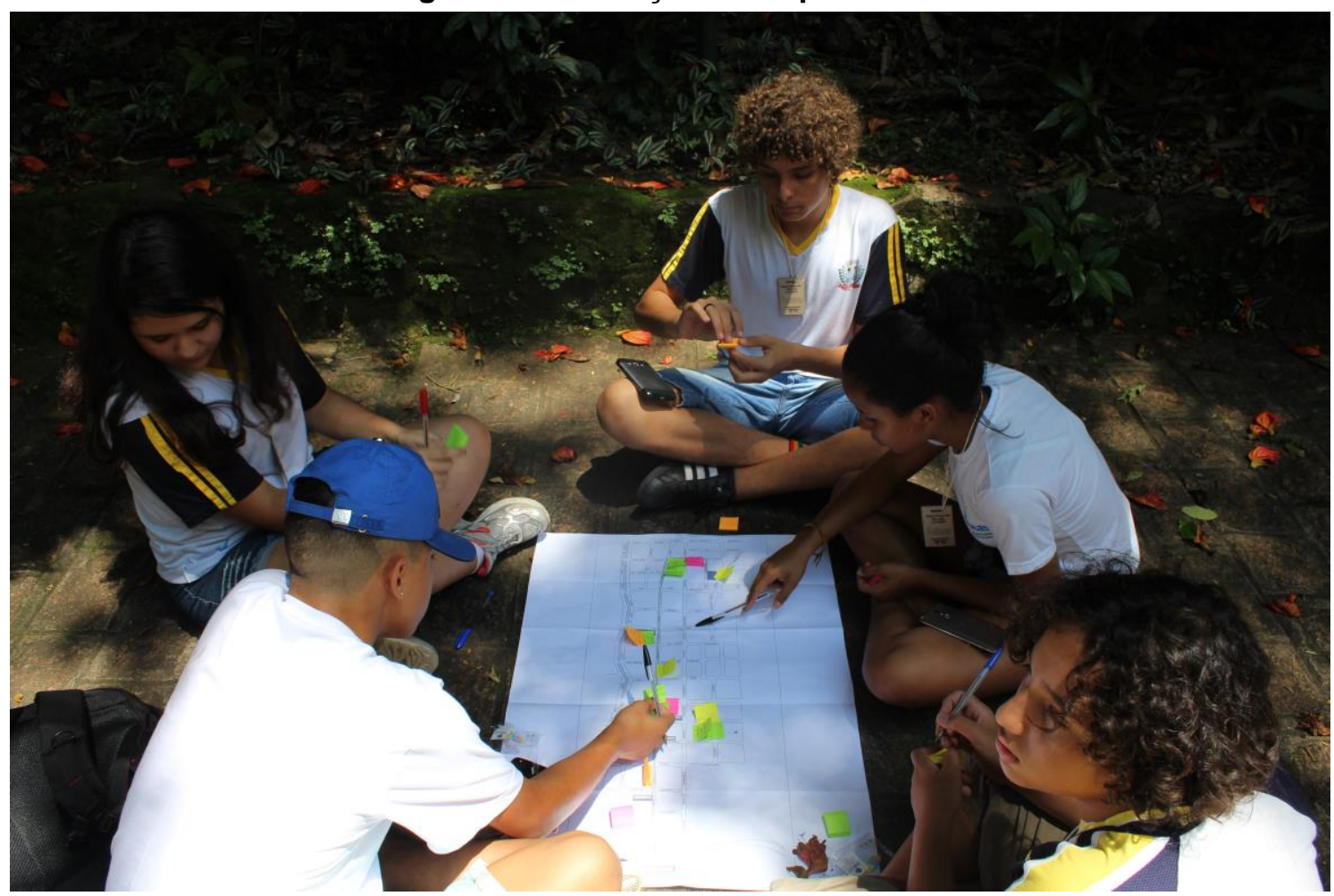

Fonte: Arquivo da pesquisa, Brotas, 2018.

Etapa 3 (Registro): Ainda com o objetivo de estimular a criatividade de cada participante e resgatar o valor do patrimônio arquitetônico da cidade, cada indivíduo elaborou uma reflexão textual expondo seu ponto de vista e sua percepção sobre os bens culturais, conforme o trecho que segue:

Durante o exercício, entrei para fotografar a fundação de um casarão antigo da cidade, lá estava a mostra toda estrutura de pedras encaixadas e uma parede construída de barro. Muitos casarões como esse já foram demolidos e assim vamos esquecendo a importância desses prédios para a história da cidade (Depoimento de Ana Leticia Bronzati, 14 anos). 
Etapa 4 (Apropriação): Com referência nos trabalhos de Willians e Dolabela e com propósito de retratar de forma gráfica a percepção, cada participante criou uma Fotocolagem digital, com auxílio de softwares de edição de imagens, como ilustra a Figura 4, sobrepondo as imagens mais representativas que identificaram sobre a arquitetura local a fim de criar uma paisagem particular do lugar.

Figura 4. Produção da Fotocolagem Digital.

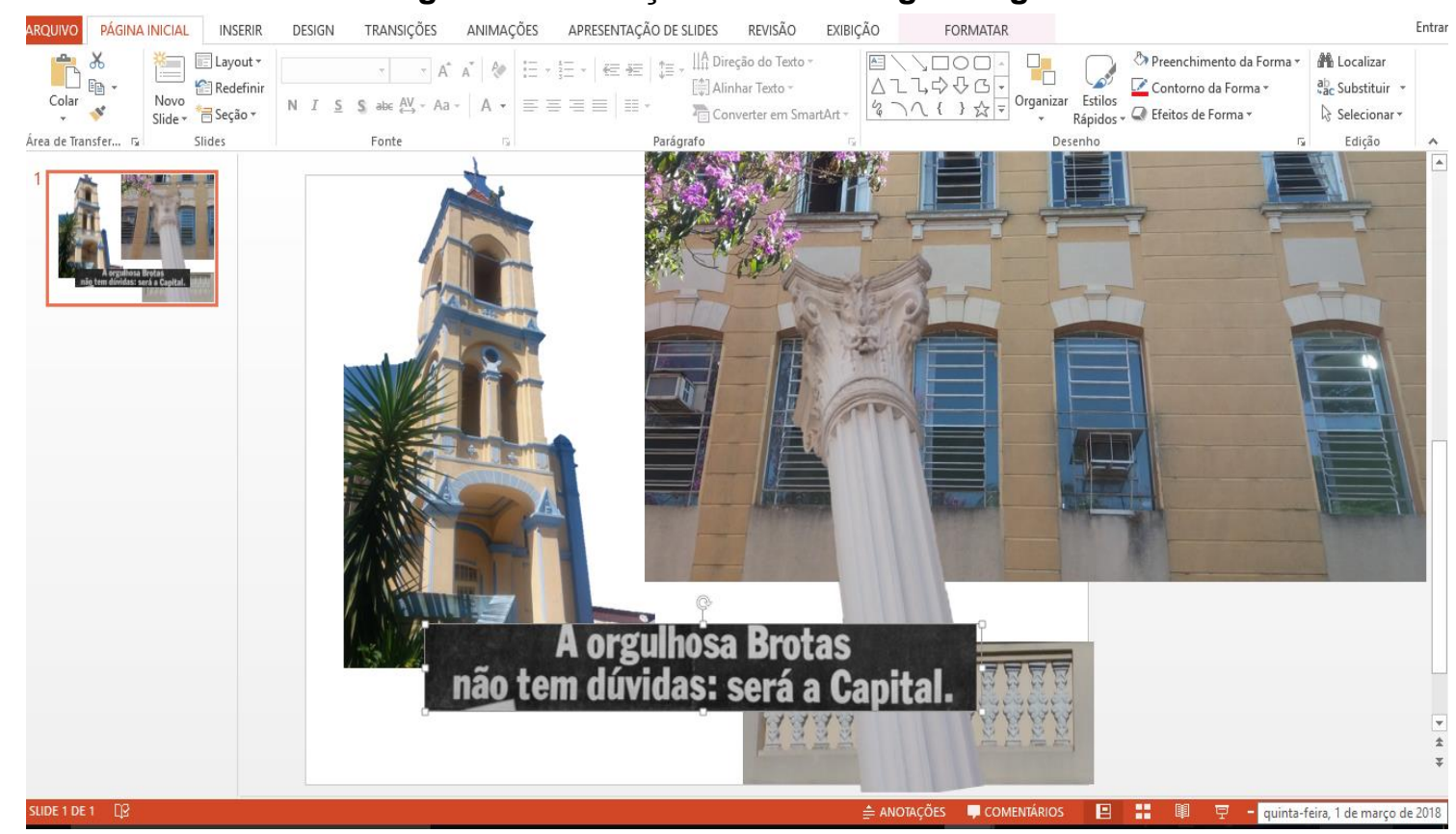

Fonte: Arquivo da Pesquisa, Brotas, 2018.

Os trabalhos finalizados foram impressos e expostos na praça central da cidade, a fim de que os moradores pudessem observar a cidade pelo olhar de cada aluno, e desse modo também ressignificar sua percepção sobre os lugares. A exposição está ilustrada pela Figura 5. 
Figura 5. Exposição das Fotocolagem na praça Central de Brotas com a presença dos participantes do workshop e pessoas da cidade.

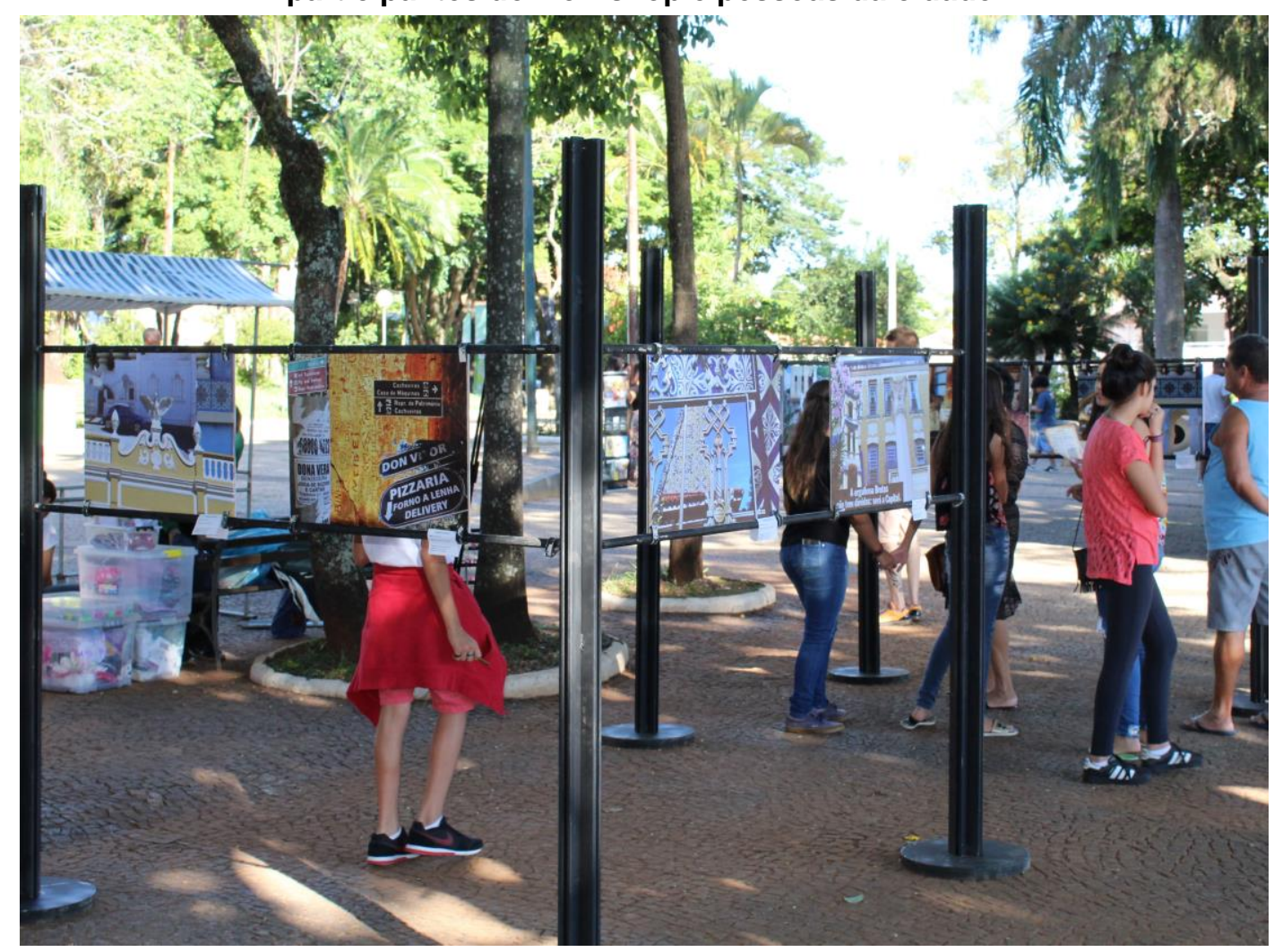

Fonte: Arquivo da Pesquisa, Brotas, 2018.

Observando a atividade foi possível identificar que o uso da fotografia auxilia a focar o olhar de maneira diferenciada para os bens culturais, conquanto para conhecer o patrimônio arquitetônico como um todo é preciso observar todos os seus eixos. Aqui cada pessoa se limitou a conhecer um eixo sobre a arquitetura e por fim puderam compartilhar os detalhes e objetos que conheceram no lugar.

\section{Resultados alcançados}

Dentre os participantes, dezessete (85\%) afirmaram ter percebido novos detalhes na cidade, três (15\%) afirmam não ter encontrado nenhuma novidade, conquanto todos admitem sentir que o patrimônio arquitetônico faz parte da construção de sua história e memória sobre a cidade. Com relação ao uso da fotografia como suporte, treze (65\%) participantes afirmam que o ato de fotografar facilitou identificar pontos específicos da arquitetura, sete (35\%) participantes acreditam que puderam observar o modo de vida e os costumes na cidade, todos 
(100\%) os participantes afirmam que por meio da fotografia puderam mostrar as imagens que mais lhe interessam.

No que diz respeito à Fotocolagem, todos (100\%) os participantes afirmam que com a atividade gráfica foi possível criar um retrato com os detalhes arquitetônicos que em sua percepção fazem parte da identidade do lugar e precisam ser preservados. Conforme citou a participante Shanaya Tartai (13 anos): "Gostaria que as pessoas ao ver meu trabalho de Fotocolagem percebessem que o patrimônio da cidade deve ser bem cuidado". Todos (100\%) os visitantes entrevistados durante a exposição disseram ver uma criticidade plástica sobre o conjunto arquitetônico da cidade. Em específico a moradora Patrícia Aparecida Babos, declarou:

O trabalho me fez refletir sobre a preciosidade do conjunto arquitetônico da cidade. É muito bacana ver o resultado ao qual os alunos chegaram, utilizando seus celulares e os softwares disponibilizados em tão pouco tempo [...]

Os resultados desse projeto fortalecem a ideia de que o conceito de Educação Patrimonial facilita a aproximação da sociedade com os bens culturais. Demonstra que na sociedade atual, com os recursos tecnológicos disponíveis, as percepções sobre o lugar podem ser construídas de forma interativa e colaborativa, fato que permite o surgimento de ressignificações sobre a identidade da cidade. De tal modo ao consentir uma nova forma de interagir com o espaço já conhecido, a atenção do observador se mostra mais focada, uma vez que ao encontrar elementos relacionados ao seu eixo motiva o indivíduo a percorrer o olhar por novos espaços que vão além dos comumente percebidos. Para o aluno Leonardo dos Santos Participante da Pesquisa:

\begin{abstract}
A fotografia me possibilitou olhar com calma a cidade, a partir do momento que realmente olhei para as casas mais antigas e para os estabelecimentos por dentro percebi seus detalhes, como portões, janelas, paredes bem desenhadas e coisas que realmente marcam a cidade, se você realmente repensar. Antes do projeto não havia notado tanta beleza e coisas históricas, tudo isso passava despercebido (Depoimento de Leonardo dos Santos, 14 anos).
\end{abstract}

Com base nesse depoimento, percebe-se que nesta ação educativa foi possível contribuir para o reconhecimento da comunidade sobre o seu patrimônio, evocando sentimentos de pertença que potencializam pensamentos críticos em relação à preservação e cuidado do local. Os recursos digitais utilizados representaram um papel importante no processo de fixação do que foi descoberto sobre a cidade, com o TARDIVO, Jessica Aline; PRATSCHKE, Anja; CARDOSO, Maria Clara. A luz da fotografia: 334 experiência de registro da percepção sobre o patrimônio arquitetônico na cidade de Brotas (SP) Revista GEARTE, Porto Alegre, v. 5, n. 2, p. 326-336, maio/ago. 2018.

Disponível em: http://seer.ufrgs.br/gearte 
registro e a facilidade de acesso aos mesmos, permitindo a retomada do que havia sito visto e o estabelecimento de outras percepções e conexões entre diversos locais. Por fim, conclui-se que a reprodução em outras cidades do método empregado nesse trabalho se mostra possível, uma vez que a atividade faz uso de tecnologias de fácil acesso e tem aplicabilidade em diversas faixas etárias. Dessa forma, a experiência educativa pode ser inserida em ações e políticas efetivas para a preservação dos lugares de memória.

\section{Referências}

DELEUZE, Gilles; GUATTARI, Félix. Mil platôs: capitalismo e esquizofrenia. Rio de Janeiro: Editora 34, V $1,1995$.

DOLABELA, Virginia. Portfólio em artes visuais. Disponível em: < https://virginiadolabela.blogspot.com.br>. Acesso em 28 nov. 2017.

HATUKA, Tali. A obsessão com a memória: o que faz conosco e com as nossas cidades (Pág. 47-60). In CYMBALISTA, Renato; FELDMAN, Sarah e KUHL, Beatriz. Patrimônio cultural memória e intervenções urbanas. São Paulo: Núcleo de Apoio e pesquisa de São Paulo, 2017.

HORTA, Maria de Lourdes Parreira: GRUNBERG, Evelina: MONTEIRO, Adriane Queiroz. Guia básico de educação patrimonial. Brasília: IPHAN; Museu Imperial, 1999.

IPHAN. Educação Patrimonial: histórico, conceitos e processos. Brasília: Instituto do Patrimônio Histórico e Artístico Nacional, 2014.

KOSSOY, Boris. Fotografia e história. Cotia: Ateliê Editorial, 2012.

WILLIAMS, Hilary. Urban-landscapes. Disponível em: <http://www.hilaryatthecircus.com/urbanlandscapes/Acesso>. Acesso em 28 nov. 2017.

WILLIAMS, Hilary. "The city" artist spotlight: Hilary Williams. São Francisco: Primeira Emenda, 2010. Disponível em < http://1amsf.com/2010/02/27/the-city-artist-spotlight-hilary-williams/>. Acesso em 15 jan. 2018.

\section{Site das pesquisas}

http://www.nomads.usp.br/pesquisas/preservacaocomosistema

http://www.nomads.usp.br/wp/patrimoniodigital/

\section{Jéssica Aline Tardivo}

Arte Educadora, Pedagoga e Arquiteta, Mestre em Educação e pesquisadora de doutorado do Nomads.usp no Instituto de Arquitetura e Urbanismo da Universidade de São Paulo. Estuda a aplicação da Educação Patrimonial, associadas às novas tecnologias, com o propósito de facilitar a identificação da herança cultural de uma cidade.

Email: jessica.tardivo@usp.br

Currículo: http://lattes.cnpq.br/2658993454212592 


\section{Anja Pratschke}

É arquiteta e Doutora em Ciência da Computação, professora e pesquisadora do Instituto de Arquitetura e Urbanismo da Universidade de São Paulo e Co-coordenadora do Nomads.usp. Desenvolve e orienta pesquisas nas áreas de processos de projeto e comunicação em arquitetura.

Email: pratschke@sc.usp.br

Currículo: http://lattes.cnpq.br/9669955733350604

\section{Maria Clara Cardoso}

Estudante de graduação em no Instituto de Arquitetura e Urbanismo da Universidade de São Paulo. Pesquisadora do grupo Nomads.usp. Desenvolve pesquisa de iniciação cientifica na área de patrimônio e mídias digitais.

Email: maria3.cardoso@usp.br

Currículo: http://lattes.cnpq.br/3877191799453612

Recebido em 22 de maio de 2018 Aceito em 10 de agosto de 2018 